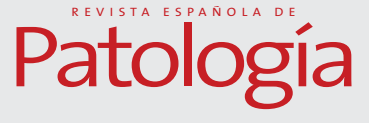

www.elsevier.es/patologia

REVISIÓN

\title{
Recomendación para la determinación de biomarcadores en el carcinoma colorrectal. Consenso Nacional de la Sociedad Española de Anatomía Patológica y de la Sociedad Española de Oncología Médica
}

\author{
Samuel Navarro ${ }^{a, *}$, Pedro Pérez-Segura ${ }^{b}$, Santiago Ramón y Cajal ${ }^{c}$, \\ Ramón Salazar ${ }^{d}$, Jesús García-Foncillas ${ }^{e}$, Eva Musulén Palet ${ }^{f}$, \\ Rocío García-Carbonero ${ }^{g}$, Artemio Payá ${ }^{\text {y }}$ y Pilar García-Alfonso ${ }^{i}$
}

\footnotetext{
a Servicio de Anatomía Patológica, Hospital Clínico Universitario de Valencia, Valencia, España

b Servicio de Oncología Médica, Hospital Clínico Universitario San Carlos, Madrid, España

c Servicio de Anatomía Patológica, Hospital Universitario Vall d'Hebron, Barcelona, España

d Servicio de Oncología Médica, ICO Hospital Duran i Reynals, Hospitalet de Llobregat, Barcelona, España

e Servicio de Oncología y Unidad de Genética Clínica, Clínica Universidad de Navarra, Pamplona, Navarra, España

f Servicio de Anatomía Patológica, Hospital Universitari Germans Trias i Pujol, Badalona, Barcelona, España

' Servicio de Oncología Médica, Hospital Universitario Virgen del Rocío, Instituto de Biomedicina de Sevilla (HUVR, CSIC, Universidad de Sevilla), Sevilla, España

h Servicio de Anatomía Patológica, Hospital General Universitario de Alicante, Alicante, España

i Servicio de Oncología Médica, Hospital General Universitario Gregorio Marañón, Madrid, España
}

Recibido el 29 de marzo de 2012; aceptado el 7 de mayo de 2012

Disponible en Internet el 30 de junio de 2012

\author{
PALABRAS CLAVE \\ Receptor del factor \\ de crecimiento \\ epidérmico; \\ Gen KRAS; \\ Gen BRAF; \\ Inestabilidad de \\ microsatélites; \\ Gen PTEN
}

\begin{abstract}
Resumen Este documento de consenso nace como una iniciativa conjunta de la Sociedad Española de Anatomía Patológica (SEAP) y de la Sociedad Española de Oncología Médica (SEOM) y propone recomendaciones diagnósticas y terapéuticas para el manejo del paciente con cáncer colorrectal (CCR) hereditario, localizado y avanzado basadas en la evidencia científica que existe en la actualidad sobre el uso de biomarcadores. Por tanto, este documento supone una oportunidad para mejorar la eficiencia de la actividad asistencial y la utilización de recursos, lo que redundará en un beneficio para estos pacientes.

Con los datos disponibles en la actualidad, este grupo de expertos recomienda que en los pacientes con CCR localizado se determine la inestabilidad de microsatélites, ya que es un factor predictivo relevante para decidir el tratamiento adyuvante. Sin embargo, aunque las firmas de expresión genética ColoPrint ${ }^{\circledR}$ y Oncotype $D x^{\circledR}$ han demostrado tener valor pronóstico, no existe todavía consenso sobre su uso en la práctica clínica.

En cuanto al CCR avanzado, la determinación del estado mutacional de KRAS es indispensable antes de administrar un tratamiento con anti-receptor del factor de crecimiento epidérmico
\end{abstract}

\footnotetext{
* Autor para correspondencia.

Correo electrónico: samuel.navarro@uv.es (S. Navarro).
} 
(EGFR), como cetuximab y panitumumab. Sin embargo, la determinación de otros biomarcadores, como las mutaciones de BRAF, EGFR, PI3K y PTEN, no debe llevarse a cabo de forma rutinaria, ya que hoy por hoy no influye en la planificación del tratamiento. Otros aspectos importantes que incluye son los requisitos organizativos y los controles de calidad que deben existir para la adecuada determinación de estos biomarcadores, así como las implicaciones legales que se deben tener en cuenta.

(c) 2012 SEAP y SEC. Publicado por Elsevier España, S.L. Todos los derechos reservados.

\section{KEYWORDS}

Epidermal growth

factor receptor;

KRAS gene;

BRAF gene;

Microsatellite

instability;

PTEN gene

\section{Guidelines for biomarker testing in advanced colorectal carcinoma. A National Consensus of the Spanish Society of Pathology and the Spanish Society of Medical Oncology}

Abstract This consensus is a joint initiative of the Spanish Society of Pathology (SEAP) and the Spanish Society of Medical Oncology (SEOM). Based on scientific evidence of the use of biomarkers, it recommends diagnostic and treatment guidelines for the management of patients with hereditary, localised and advanced colorectal carcinoma (CRC). The aim of the consensus is to improve healthcare and the use of resources, which will result in increased patient benefit.

Taking into consideration data currently available, the group of experts recommends testing for microsatellite instability in patients with localised CRC, as this is a strong predictive factor useful in deciding the choice of adjuvant treatment. However, although the ColoPrint ${ }^{\circledR}$ and Oncotype $D x^{\circledR}$ gene expression signatures have been shown to have prognostic value, no consensus yet exists as to their clinical use.

For advanced CRC, it is essential to test for KRAS mutation status before administering an anti-epidermal growth factor receptor (EGFR) treatment, such as cetuximab or panitumumab. However, at present, testing for other biomarkers, such as BRAF, EGFR, PI3K and PTEN mutations, is not indicated as a routine procedure as it does not influence choice of treatment. Other important issues addressed include organisational requirements, necessary quality controls for the correct testing of these biomarkers as well as the pertinent legal implications.

(c) 2012 SEAP y SEC. Published by Elsevier España, S.L. All rights reserved.

\section{Introducción}

Recientemente el sector sanitario ha promovido la elaboración de guías de práctica clínica, lo que ha supuesto un aumento de la efectividad de la intervención oncológica en base a los niveles de evidencia científica y en el consenso profesional. En este sentido, no existen guías clínicas específicas sobre el uso de biomarcadores en el cáncer colorrectal (CCR).

La alta incidencia de CCR, y el impacto sociosanitario que ello supone, hace necesaria la elaboración de protocolos de consenso por parte de los equipos multidisciplinares que intervienen en el diseño de las distintas estrategias terapéuticas. Para colaborar en el objetivo fundamental de conseguir la curación de los enfermos, o al menos de mejorar su supervivencia y su calidad de vida, es necesario mantener una comunicación fluida y homogénea entre oncólogos y patólogos. Por otro lado, la utilización de estos protocolos consensuados conllevará la obtención de un impacto económico favorable, debido a que se optimizará la administración de los tratamientos más adecuados a cada caso.

Una de las revoluciones terapéuticas que está sucediendo en la actualidad se basa en el conocimiento de los biomarcadores que intervienen en las rutas moleculares de las células cancerosas, frente a las que se han diseñado medicamentos que bloquean algunas de ellas, y por lo que han pasado a formar parte del arsenal terapéutico disponible.
Otros biomarcadores, como los genes de la vía reparadora del ácido desoxirribonucleico (ADN) o el gen APC, ya se analizan de forma rutinaria para determinar la susceptibilidad del sujeto a padecer CCR hereditario. Estas nuevas estrategias terapéuticas crean la necesidad de que oncólogos y patólogos trabajen juntos, asegurando la disponibilidad de la muestra necesaria para realizar la determinación de estos marcadores en los laboratorios pertinentes.

Aunque en la mayoría de los casos el material procedente de las resecciones quirúrgicas del CCR garantiza la obtención de muestra suficiente, se ha de tener en cuenta que en determinadas circunstancias este material puede ser limitado y escaso. Esto sucederá especialmente cuando solo se disponga de biopsias endoscópicas o punciones de la enfermedad metastásica, o incluso cuando solo exista tumor residual mínimo tras un tratamiento neoadyuvante. Por todo ello, el patólogo debe asumir la responsabilidad de optimizar el uso de las muestras, y su trazabilidad en el supuesto de que las determinaciones de biomarcadores se realicen en laboratorios diferentes.

Una cuestión fundamental que será tratada en esta guía hace referencia a la optimización y homogeneización de la metodología utilizada para la determinación de biomarcadores. Además, para asegurar la efectividad y especificidad de los resultados, es necesaria la aplicación de controles de calidad internos o externos como los que se llevan a cabo a través de sociedades científicas como la Sociedad Española 
de Oncología Médica (SEOM) y la Sociedad Española de Anatomía Patológica (SEAP).

Otro tema importante que será analizado en esta guía hace referencia a las implicaciones legales y a los aspectos bioéticos existentes en el manejo de pacientes oncológicos. La aplicación de la nueva Ley de Investigación Biomédica obliga a tener en cuenta aspectos éticos, como la obtención del consentimiento informado y la normativa de almacenamiento de excedentes de muestra en los diferentes biobancos. Así, la obtención del consentimiento informado es crucial, teniendo en cuenta que alguna de las pruebas genéticas, como la inestabilidad de microsatélites (MSI), puede proporcionar información que repercuta en el ámbito familiar del paciente, por lo que el paciente puede negarse a que se realice.

Esta guía demuestra el grado de consenso que existe entre patólogos y oncólogos, y pretende establecer con claridad y concisión cuando es necesario analizar los diferentes marcadores de susceptibilidad hereditaria del CCR, así como otros biomarcadores con carácter pronóstico y predictivo. Además, esta guía es susceptible de ser revisada de forma periódica, para incorporar nuevos biomarcadores cuyo nivel de evidencia científica aconseje su empleo, ya sea en el marco de ensayos clínicos o de futuras estrategias terapéuticas.

\section{Aspectos clínicos}

\section{Marcadores de susceptibilidad del cáncer colorrectal hereditario}

Cada año se diagnostican en nuestro país unos 26.000 casos de CCR; de ellos, entre el 5 y el $10 \%$ presentan un patrón claramente hereditario, y hasta el $25 \%$ tienen un patrón familiar. La identificación de estos casos es enormemente importante para incrementar la tasa de diagnósticos precoces. Solo hay que recordar que el diagnóstico precoz del CCR puede conllevar tasas de curación de hasta el $90 \%$, lo cual es similar a las tasas conseguidas mediante el cribado mamario.

Dentro de los cuadros hereditarios que existen en CCR, se puede dividir a la población en pacientes con síndrome de Lynch - también llamado cáncer de colon hereditario no polipósico- y pacientes con síndrome polipósico, los cuales a su vez se subdividen en adenomatosos y no adenomatosos.

\section{Síndrome de Lynch}

Cuando se identifica un paciente con síndrome de Lynch mediante los criterios clínicos de sospecha Amsterdam I y Amsterdam $\|^{1,2}$, se debe ofrecer al paciente la posibilidad de determinar si existe alguna mutación en la familia de los genes de reparación de errores de apareamiento (MMR), fundamentalmente $\mathrm{MLH1}, \mathrm{MSH} 2, \mathrm{MSH} 6$ y $\mathrm{PMS} 2$, en el marco de un asesoramiento genético adecuado ${ }^{3}$. Para ello se debe seguir un algoritmo de actuación claro, conciso y consensuado por los grupos que trabajan en este campo, como el que se muestra en la figura 1. Así, el primer paso en un paciente con criterios clínicos de sospecha debe ser el análisis de la MSI o de la falta de expresión de las proteínas producidas por estos genes, mediante inmunohistoquímica (IHQ). En función de la presencia o no de mutaciones en los
Tabla 1 Síndromes hereditarios de cáncer colorrectal y genes asociados ${ }^{a}$

\begin{tabular}{ll}
\hline Síndrome & Gen \\
\hline Síndrome de Lynch & MLH1 \\
& MSH2 \\
& $M S H 6$ \\
& $P M S 2$ \\
& $E P C A M$ \\
Poliposis adenomatosa familiar & APC \\
& $M Y H$ \\
Poliposis juvenil & SMAD4 \\
& BMPa \\
Síndrome de Cowden & $P T E N$ \\
Síndrome de Peutz-Jeghers & STK11 \\
\hline a Estas alteraciones genéticas se determinan a nivel germinal.
\end{tabular}

genes MMR, se podrá orientar de forma más específica sobre el riesgo que tienen los portadores para desarrollar alguno de los cánceres asociados al síndrome de Lynch, así como las medidas más idóneas de seguimiento en cuanto a pruebas, periodicidad y edad de comienzo ${ }^{3}$.

En algunos casos de CCR no familiar también se puede recomendar la realización del análisis de la MSI, dado que hasta el $10 \%$ de estos CCR pueden expresarlo ${ }^{4}$. Es más, recientemente se ha propuesto ampliar las indicaciones de este tipo de análisis a cualquier CCR o cáncer endometrial, al resultar ser coste-efectivo, al menos en el CCR. Por último, existen modelos matemáticos que pueden ayudar a determinar las posibilidades de que una familia presente una mutación en los genes $M M R^{5}$.

\section{Síndromes polipósicos}

En la tabla 1 se recogen los genes asociados tanto a los síndromes polipósicos como no polipósicos. En relación con las poliposis, no existen hasta la fecha marcadores moleculares que nos permitan identificar estos casos. Por tanto, la selección inicial de las familias se hace por criterios exclusivamente clínicos y posteriormente se procede al estudio de mutaciones germinales en los genes implicados en cada uno de ellos. Hay que recordar que hasta el $30 \%$ de los casos de poliposis adenomatosa familiar no presentan más que el caso índice, sin otros antecedentes en la familia. En cualquier caso, este dato no debe influir a la hora de proponer la realización del estudio genético.

En base a estas premisas, este panel de expertos recomienda que:

Para detectar marcadores de susceptibilidad al CCR hereditario se realice un precribado a los familiares de los pacientes con CCR, teniendo en cuenta los criterios clínicos de sospecha de Amsterdam y Bethesda (nivel de evidencia lla).

- Si no hay MSI, ni pérdida de expresión de ninguna proteína reparadora, no se debe continuar el estudio genético del paciente, dada la baja probabilidad que existe de identificar una mutación patogénica en los genes reparadores (nivel de evidencia lla). 


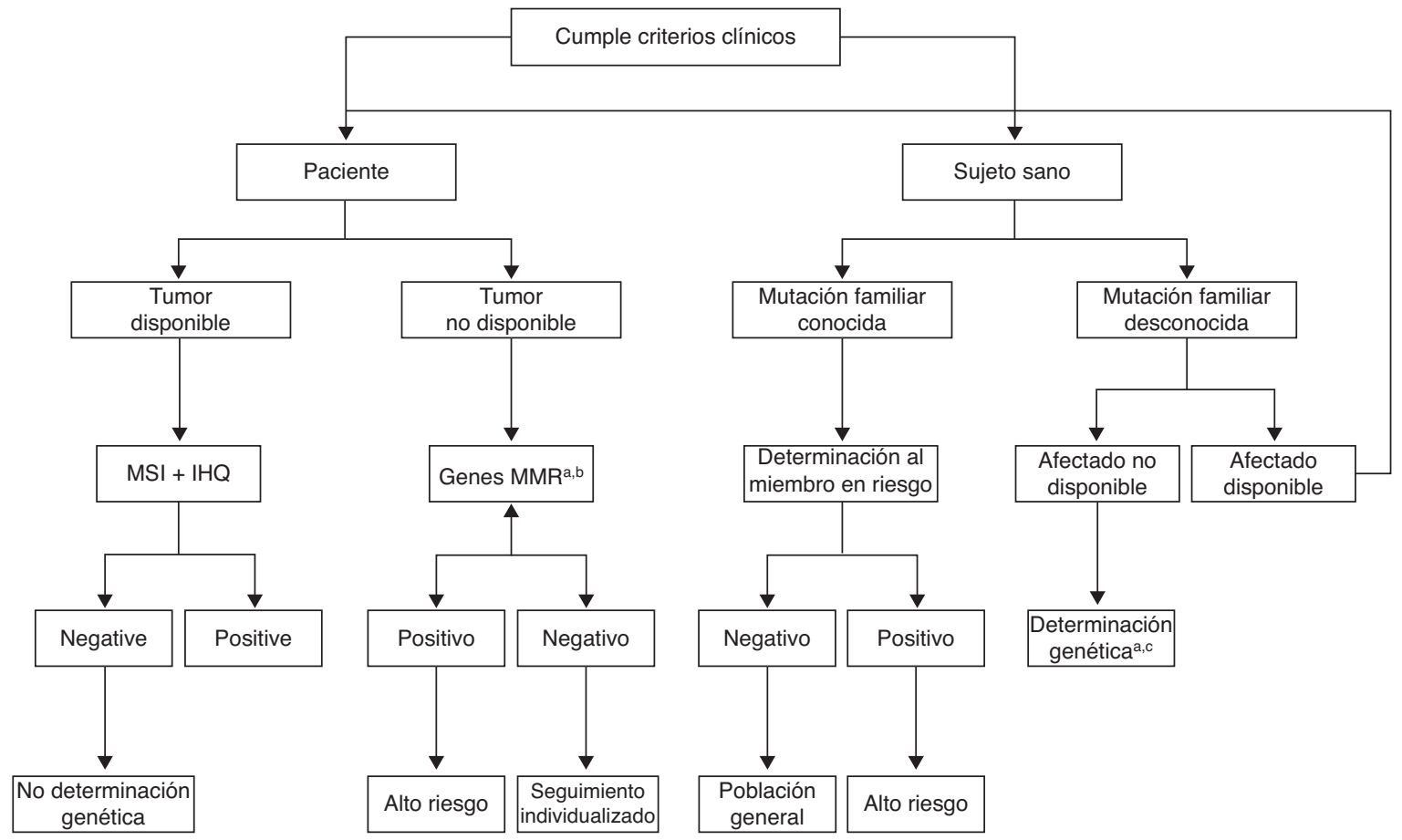

Figura 1 Algoritmo de actuación para detectar el síndrome de Lynch.

a Valorar a nivel individual. ${ }^{b}$ Cuando no haya tumor disponible pero se cumplan los criterios de Amsterdam y las implicaciones para la familia sean importantes, se debe valorar la opción de hacer un estudio de mutaciones germinales en genes MMR directamente. 'Cuando no haya afectos vivos o disponibles, se valorará hacer el estudio germinal en un sujeto sano, siempre y cuando la repercusión para el manejo de la familia sea importante.

IHQ: inmunohistoquímica; MMR: genes de reparación de errores de apareamiento replicativo; MSI: inestabilidad de microsatélites.

\section{Marcadores moleculares del cáncer colorrectal localizado}

La tumorigénesis en el CCR está impulsada por la acumulación de un número limitado de alteraciones genéticas en los oncogenes y en los genes supresores de tumores. El conocimiento de estos es profundo, pero su aplicabilidad clínica ha sido difícil de conseguir hasta hace poco tiempo. La falta de procedimientos de validación estandarizados de los nuevos biomarcadores moleculares pronósticos y predictivos puede explicar en parte esta lenta transición a la clínica.

\section{Pérdida de heterocigosidad de $18 \mathrm{q}$}

Existen estudios que sugieren que la pérdida de heterocigosidad (LOH) de $18 \mathrm{q}$ es un biomarcador pronóstico ${ }^{6}$, siendo las pérdidas de expresión de DCC y SMAD4 las dianas moleculares putativas implicadas ${ }^{7,8}$. Sin embargo, los datos obtenidos en el estudio más robusto que aborda esta cuestión dentro del ensayo prospectivo y aleatorizado PETACC-3 no han validado este biomarcador pronóstico cuando el análisis se controlaba por el estado de la MSI, tanto en estadio II como en estadio $1 \mathrm{II}^{9}$. De igual forma, un estudio realizado en una cohorte de 555 tumores con microsatélites estables, que incluía estadios I-IV, descartó el valor pronóstico de LOH de $18 q^{10}$.

\section{Inestabilidad de microsatélites}

Por el contrario, el valor pronóstico de la MSI, también sugerido inicialmente por un metaanálisis de estudios retrospectivos y heterogéneos ${ }^{11}$, ha sido validado mediante varios análisis asociados a grandes estudios prospectivos fase III9,12-14. Así, los resultados del estudio PETACC-3 validan este efecto en el estadio II, aunque no en el estadio III (razón de riesgo [HR]: 0,28; intervalo de confianza [IC] del 95\%: $0,1-0,72 ; p=0,0089)^{9}$. En el análisis secundario del estudio QUASAR, la MSI evaluada mediante IHQ de las proteínas reparadoras fue el factor de riesgo pronóstico más relevante con respecto a la recaída (HR: 0,53; IC 95\%: 0,40-0,70; $\mathrm{p}<0,001)^{13}$.

Por tanto, aunque el potencial de la MSI como marcador predictivo negativo con respecto al beneficio que aporta la quimioterapia adyuvante es controvertido ${ }^{15}$, la MSI es el único biomarcador pronóstico que ha sido suficientemente validado en estudios prospectivos e independientes mediante análisis multivariantes, en los que se incluyen otros factores de riesgo clinicopatológicos relevantes.

\section{Firmas de expresión génica}

Los cambios genéticos detectados en CCR pueden dar lugar a cambios globales en el transcriptoma que se confirman exhaustivamente a través de técnicas de alto rendimiento.

Varios estudios han evaluado el valor pronóstico de los perfiles de expresión, obteniendo resultados prometedores $^{16-24}$. Sin embargo, estos estudios tienen limitaciones importantes, ya que a) utilizan un número limitado de muestras para generar las firmas de expresión génica; 
b) carecen de una cohorte externa e independiente de muestras que validen los hallazgos obtenidos, y c) no disponen de comparaciones entre estos parámetros moleculares y los factores clinicopatológicos utilizados habitualmente en la práctica clínica.

Sin embargo, existen dos plataformas comerciales que han superado estas limitaciones. Una de ellas, la firma génica Oncotype $D x^{\circledR}$ de CCR, ya se comercializa en Estados Unidos. Esta prueba se desarrolló inicialmente al analizar de forma aleatoria 761 genes candidatos de muestras obtenidas de pacientes con cáncer de colon estadioll y III incluidos en los ensayos clínicos NSABP C-01/C-02/C04/C-06 y CCF mediante técnicas de transcripción reversa de la reacción en cadena de la polimeración $(\mathrm{RT}-\mathrm{PCR})^{25}$. Así, se seleccionaron 7 genes con valor pronóstico y 6 genes con valor predictivo para ser validados como firmas génicas. Para ello, se analizaron de forma prospectiva 1.200 muestras de pacientes incluidos en el ensayo QUASAR y los resultados se correlacionaron con la evolución de los pacientes. De esta forma se consiguió validar el valor pronóstico de la firma génica, estableciendo 3 categorías de riego (alto, intermedio y bajo) con tasas de recaída a los 3 años del 22 , del 18 y del $12 \%(p=0,046)$, respectivamente. Sin embargo, el valor predictivo de la firma génica no pudo ser validado, lo cual compromete la utilidad clínica de esta prueba $^{26}$.

La otra plataforma comercial, ColoPrint ${ }^{\circledR}$, se ha desarrollado como prueba con valor pronóstico mediante micromatrices multigénicas de ácido desoxirribonucleico complementario (ADNc) en Agilent de $44 \mathrm{~K}$, utilizando muestras de tumor frescas y un planteamiento inicial agnóstico. Así, se pudo crear una firma de expresión de 18 genes, más robusta, que clasifica a los pacientes como de alto o bajo riesgo de recaída, independientemente de factores clinicopatológicos ${ }^{27}$. Esta plataforma ha sido recientemente validada en una serie independiente, en la cual se demuestra mediante un análisis multivariante que ColoPrint ${ }^{\circledR}$ tiene valor pronóstico para la supervivencia libre de recaída (SLR) (HR: 2,69; IC 95\%: 1,41-5,14; $p=0,003$ ), especialmente en pacientes en estadio II (HR: $3,34 ; p=0,017)^{28}$. Otra serie independiente ha generado resultados similares ${ }^{29}$, mientras que está en marcha un estudio prospectivo de confirmación, el PARSC (Prospective Study for the Assessment of Recurrence Risk in Stage II Colon Cancer Patients Using ColoPrint ${ }^{T M}$ NCT00903565; http://165.112.8.96/ct2/show/results/NCT00903565). Por tanto, aunque los resultados de ColoPrint ${ }^{\circledR}$ con casi una diferencia en el riesgo de SLR del $20 \%$ son alentadores, necesitan ser validados mediante estudios prospectivos e independientes antes de recomendar su uso en la práctica clínica.

Por último, la firma génica desarrollada por Almac Diagnostics en muestras de tumor incluidas en parafina y fijadas con formalina ha sido recientemente validada en una serie retrospectiva e independiente de pacientes. Sin embargo, en el estudio no se describe el estado de la MSI. Esto supone un gran problema, ya que es imposible estimar la contribución relativa de este marcador al rendimiento de esta nueva firma génica ${ }^{30}$.

En resumen, aunque se han desarrollado muchos biomarcadores moleculares individuales para el CCR localizado y las firmas de expresión génica han dado lugar a resultados prometedores, en la actualidad solo el valor pronóstico de la MSI está suficientemente validado para ser utilizado en la práctica clínica.

En base a estas premisas, este panel de expertos recomienda que:

Los pacientes con CCR estadio II y MSI no sean candidatos a recibir quimioterapia adyuvante, ya que tienen un bajo riesgo de recaída y no existe evidencia científica del beneficio que este tratamiento puede aportarles (nivel de evidencia lla).

\section{Marcadores moleculares del cáncer colorrectal metastásico}

Subyacente al receptor del factor de crecimiento epidérmico (EGFR), y tras la activación del mismo, la señal puede transmitirse a través de 3 grandes vías de señalización intracelular: a) mediante la activación de RAS-BRAF-MAPK; b) mediante la activación de PI3K-AKT-PTEN-mTOR, y c) mediante la vía del transductor de señal y activador de la transcripción 3 (STAT3). Por tanto, existen distintos conductores de la señal proliferativa, como KRAS, BRAF, EGFR, PI3K y PTEN.

\section{KRAS}

Dentro de la familia de genes RAS, se conocen los 3 miembros $H$-RAS, N-RAS y KRAS, siendo este último el que presenta mutaciones con mayor frecuencia en el CCR. Estos genes codifican, en condiciones normales, una serie de proteínas RAS, las cuales transmiten la señalización producida mediante la activación de los receptores de membrana. La proteína RAS inactiva está unida al guanosín difosfato (GDP) $y$, al estimularse, un factor intercambiador de nucleótidos de guanina (GEF) favorece la formación del complejo guanosín trifosfato (GTP)-RAS, que es la forma activa de la proteína. De forma breve, dicho GTP es hidrolizado a GDP por la actividad de una GTPasa intrínseca de las proteínas RAS, inactivándose. Sin embargo, cuando existen mutaciones de KRAS, la actividad GTPasa queda bloqueada y la proteína RAS permanece constitutivamente activada y unida a GTP. Dichas mutaciones suelen ocurrir en los codones 12 y 13 y, con mucha menos frecuencia, en el codón 61.

Es importante señalar que, aunque en pacientes con CCR estadioll y III el estado de KRAS no ha demostrado tener valor pronóstico, tal y como se desprende del estudio realizado sobre un total de 1.564 muestras obtenidas de 3.278 pacientes reclutados en varios ensayos clínicos con quimioterapia adyuvante (PETACC-3, EORTC 40993 y SAKK 60-00) ${ }^{31}$, en pacientes con CCR metastásico el estado de KRAS influye decisivamente a la hora de planificar el tratamiento del paciente.

El estudio CRYSTAL evalúa el beneficio de añadir cetuximab al esquema con ácido folínico, fluorouracilo e irinotecán (FOLFIRI) como tratamiento de primera línea en pacientes con CCR metastásico. En este estudio, el porcentaje de pacientes con análisis de KRAS fue del $89 \%$, de los que el $37 \%$ tenían KRAS mutado. En el grupo de pacientes con KRAS no mutado, la adición de cetuximab incrementó de forma significativa la supervivencia libre de progresión (SLP) (9,9 vs. 8,4 meses; HR: 0,696; $p=0,0012)$, la supervivencia global (SG) $(23,5$ vs. 20,0 meses; HR: 0,$796 ; p=0,0093)$ y la 
tasa de respuesta global (RG) (57,3\% vs. 39,7\%; HR: 2,069; $\mathrm{p}<0,001)^{32,33}$

El ensayo clínico fase II aleatorizado OPUS (Oxaliplatin and Cetuximab in First-Line Treatment of Metastatic Colorectal Cancer) evaluó el estado de KRAS en 315 muestras, que suponen el $93 \%$ de los pacientes reclutados, en las que no estaba mutado en 179 (57\%). En estos pacientes se observó que la adición de cetuximab al esquema de fluorouracilo, leucovorin y oxaliplatino (FOLFOX)-4 como primera línea de tratamiento del CCR metastásico benefició solo a los pacientes con KRAS nativo, aumentando significativamente la SLP (8,3 meses vs. 7,2 meses; HR: 0,$567 ; p=0,0064)$ y la tasa de RG $(57,3 \%$ vs. $34,0 \%$; HR: 2,$551 ; p=0,0027)$ con respecto a los pacientes tratados solo con FOLFOX-4. Sin embargo, el incremento observado en la SG no alcanzó la significación estadística en estos pacientes ( 22,8 vs. 18,5 meses; HR: $0,855 ; p=0,39)^{34,35}$.

El estudio CELIM incluyó 114 pacientes de 17 centros de Alemania y Austria que se aleatorizaron para recibir cetuximab más FOLFOX-6 (56 pacientes) o cetuximab más FOLFIRI $(55 \text { pacientes })^{36}$. El objetivo primario era la tasa de RG según los Criterios de Evaluación de Respuesta en Tumores Sólidos (RECIST). La respuesta parcial o completa se confirmó en el $68 \%$ de los pacientes del grupo A y en el $57 \%$ del grupo B, con una diferencia entre los grupos del 11\% (IC 95: -8-30; HR: $1,62[0,74-3,59] ; p=0,23)$. La resección $\mathrm{RO}$ se consiguió en el $20 \%$ del grupo A y en el $30 \%$ del grupo B. La tasa de RG en el grupo con KRAS nativo fue del $70 \%$ vs. $41 \%$ en los pacientes con KRAS mutado (HR: 3,42 [1,35-8,66]; $\mathrm{p}=0,0080$ ).

El ensayo clínico aleatorizado COIN comparó 3 esquemas como tratamientos de primera línea en pacientes con CCR metastásico ${ }^{37}$. En la rama $A$ se administró oxaliplatino más fluoropirimidinas (capecitabina o 5-fluorouracilo en perfusión más leucovorin); en la rama $B$ se dio el mismo esquema más cetuximab, y en la rama $C$ se administró quimioterapia intermitente. Al comparar los resultados obtenidos en las ramas $A$ y $B$ se observó que en 1.316 pacientes $(81 \%)$ en los que se analizó KRAS, 565 (43\%) mostraron KRAS mutado. En los pacientes con KRAS nativo no se observaron diferencias en términos de SLP entre la rama $A$ (8,6 meses; rango intercuartílico [IQR]: $5,0-12,5)$ y la rama $B$ con cetuximab (8,6 meses; IQR: 5,1-13,8; HR: 0,96; IC 95\%: 0,82-1,12; $\mathrm{p}=0,60)$. Tampoco se apreciaron diferencias en la SG, con una mediana de 17,9 meses (IQR: $10,3-29,2$ ) en la rama $A$ y de 17,0 meses (IQR: 9,4-30,1) en la rama B (HR: 1,04; IC 95\%: $0,87-1,23 ; p=0,67)$. En cambio, la tasa de RG sí mostró un aumento significativo $(p=0,049)$ en la rama con cetuximab $(64 \%)$, con respecto a la rama tratada solo con quimioterapia (57\%).

Un consorcio de 11 hospitales de 7 países europeos logró reunir 1.022 muestras (949 en bloques de parafina y 73 de tejido fresco congelado) de pacientes tratados con cetuximab entre los años 2001 y $2008^{38}$. Se observó que el $40 \%$ de los tumores (299 de un total de 747 muestras analizadas) eran portadores de mutación en KRAS. La tasa de RG fue del $35,8 \%$ en los pacientes con KRAS nativo, con respecto al $6,7 \%$ observado en pacientes con KRAS mutado (HR: 0,13; IC 95\%: 0,07-0,22; $p<0,0001)$. La mediana de SLP fue de 24 semanas vs. 12 semanas (HR: 1,98; IC 95\%: 1,66-2,36; $p<0,0001$ ) y la mediana de SG mostró un valor favorable para los pacientes sin mutación de KRAS (50 vs. 32 semanas; HR: 1,75; IC 95\%: 1,47-2,09; $p<0,0001)$.
A partir de los pacientes incluidos en los ensayos CO.17, BOND, MABEL, EMR202600, EVEREST, BABEL y SALVAGE, se evaluó si todas las mutaciones de KRAS manifestaban el mismo impacto pronóstico ${ }^{39}$. Se comprobó que los pacientes con la mutación G13D mostraban, con respecto al resto de las mutaciones, una SLP significativamente mejor $(4,0$ meses; IC 95\%: 1,9-6,2 vs. 1,9 meses; IC 95\%: 1,8-2,8) con una HR ajustada de 0,51 (IC 95\%: 0,32-0,81; $p=0,004$ ), así como un beneficio significativo en la SG de 7,6 meses (IC 95\%: 5,7-20,5) vs. 5,7 meses (IC 95\%: 4,9-6,8) con una HR ajustada de 0,50 (IC 95\%: 0,31-0,81; $p=0,005$ ). Los estudios en líneas celulares y en modelos animales muestran que las líneas con la mutación $\mathrm{G} 12 \mathrm{~V}$ son insensibles al cetuximab, mientras que aquellas con G13D muestran una sensibilidad similar a las líneas celulares nativas.

Por último, el ensayo clínico fase III PRIME (Panitumumab Randomized Trial in Combination With Chemotherapy for Metastatic Colorectal Cancer to Determine Efficacy) demostró en pacientes con KRAS nativo un beneficio estadísticamente significativo en la SLP para el grupo tratado con panitumumab y FOLFOX-4 (10,0 meses; IC 95\%: 9, 3-11,4) con respecto al grupo tratado solo con FOLFOX-4 (8,6 meses; IC 95\%: 7,5-9,5; HR: 0,80; IC 95\%: 7,5-9,5; $p=0,009)^{40}$. La tasa de RG también reflejó un incremento significativo en el grupo tratado con panitumumab, con un 57\% (IC 95\%: 5163) vs. 48\% (IC 95\%: 42-53) observado en el grupo control (HR: 1,47; IC 95\%: 1,07-2,04; $p=0,018$ ). En términos de SG, no se observaron diferencias significativas a favor de panitumumab con respecto al brazo control (23,9 vs. 19,7; HR: 0,83; IC 95\%: 0,67-1,02; p=0,072). No obstante, en el congreso de la Sociedad Americana de Oncología Clínica (ASCO) de 2011 se presentó una re-evaluación de los resultados de $\mathrm{SG}^{41}$, aplicando un análisis de sensibilidad mediante la aproximación de Branson-Whitehead que mostraba para los casos de KRAS nativo un valor de HR de 0,74 (IC 95\%: 0,61-0,90; $\mathrm{p}=0,003)$. En la tabla 2 se resumen los resultados obtenidos en los estudios fase III llevados a cabo en pacientes con CCR metastásico y KRAS mutado.

\section{BRAF}

El gen $B R A F$, que codifica uno de los principales efectores intracelulares de KRAS, está mutado en el $5-10 \%$ de los pacientes con $\mathrm{CCR}^{38}$. La mutación más frecuente ( 90\%) es la sustitución V600E, y está localizada en el dominio cinasa de la proteína (exon 15). Las mutaciones de BRAF son mutuamente excluyentes con las mutaciones de KRAS, de forma que estas nunca están presentes en tumores KRAS mutados y viceversa, y se asocian con la presencia de alta inestabilidad de microsatélites (MSI-H) secundaria a defectos adquiridos en la función de las enzimas del sistema $M M R^{13,31}$. Fuera de este contexto, y particularmente en enfermedad avanzada, la presencia de mutaciones $B R A F$ se asocia con un peor pronóstico 13,31,33,34,38,42,43.

Sin embargo, como factor predictivo de la respuesta a terapias dirigidas frente a EGFR, su papel es más controvertido. Si bien existen estudios no controlados que han observado de manera consistente que los pacientes con tumores KRAS nativos, pero con mutaciones de BRAF, tratados con anti-EGFR tienen tasas de RG (8,3\% vs. 38\%; HR: 0,15; $\mathrm{p}=0,0012$ ), SLP (8 vs. 26 semanas; HR: 3,74; $\mathrm{p}<0,0001)$ y SG (26 vs. 54 semanas, HR: 3,03; $p<0,0001)$ inferiores a 
Tabla 2 Impacto del tratamiento con anticuerpos anti-EGFR en pacientes con cáncer colorrectal metastásico y KRAS no mutado

\begin{tabular}{|c|c|c|c|}
\hline & $\begin{array}{l}\text { RG } \\
A C+Q T \text { vs. QT }\end{array}$ & $\begin{array}{l}\text { SLP } \\
A C+Q T \text { vs. QT }\end{array}$ & $\begin{array}{l}\text { SG } \\
A C+Q T \text { vs. QT }\end{array}$ \\
\hline CRYSTAL 33 & $\begin{array}{l}57,3 \% \text { vs. } 39,7 \% \\
\text { HR: } 2,069 \\
p<0,001\end{array}$ & $\begin{array}{l}9,9 \text { vs. } 8,4 \text { meses } \\
\text { HR: } 0,696 p=0,0012\end{array}$ & $\begin{array}{l}23,5 \text { vs. } 20,0 \text { meses } \\
\text { HR: } 0,796 ; p=0,0093\end{array}$ \\
\hline OPUS $^{34}$ & $\begin{array}{l}57,3 \% \text { vs. } 34,0 \% \\
\text { HR: } 2,551 \\
p=0,0027\end{array}$ & $\begin{array}{l}8,3 \text { vs. } 7,2 \text { meses } \\
\text { HR: } 0,567 \\
p=0,0064\end{array}$ & $\begin{array}{l}22,8 \text { vs. } 18,5 \text { meses } \\
\text { HR: } 0,855 \\
p=0,39\end{array}$ \\
\hline $\operatorname{COIN}^{37}$ & $\begin{array}{l}64 \% \text { vs. } 57 \% \\
p=0,049\end{array}$ & $\begin{array}{l}8,6 \text { vs. } 8,6 \text { meses } \\
\text { HR: } 0,96 \\
p=0,60\end{array}$ & $\begin{array}{l}17,9 \text { vs. } 17,0 \text { meses } \\
\text { HR: } 1,04 \\
p=0,67\end{array}$ \\
\hline PRIME $^{40}$ & $\begin{array}{l}57 \% \text { vs. } 48 \% \\
\text { HR: } 1,47 \\
p=0,018\end{array}$ & $\begin{array}{l}10,0 \text { vs. } 8,6 \text { meses } \\
\text { HR: } 0,80 \\
p=0,009\end{array}$ & $\begin{array}{l}23,9 \text { vs. } 19,7 \text { meses } \\
\text { HR: } 0,88 \\
p=0,072\end{array}$ \\
\hline
\end{tabular}

AC: anticuerpo; HR: razón de riesgo; QT: quimioterapia; RG: respuesta global; SG: supervivencia global; SLP: supervivencia libre de progresión.

las observadas en pacientes con tumores $B R A F$ nativos ${ }^{38}$, los escasos datos disponibles de ensayos aleatorizados sugieren que estos peores resultados son independientes del tratamiento recibido $33,34,42$. En el estudio CRYSTAL, en el que se aleatorizó a los pacientes con CCR metastásico a recibir FOL$\mathrm{FIRI} \pm$ cetuximab, la tasa de RG, SLP y SG se incrementaron significativamente al añadir cetuximab a la quimioterapia convencional en pacientes KRAS y BRAF nativos $(n=566)^{33}$. Sin embargo, una tendencia similar, aunque de menor magnitud y sin alcanzar la significación estadística, se observó en pacientes KRAS nativo y BRAF mutado $(\mathrm{n}=59)(\mathrm{RG}: 19,2 \%$ vs. $15,2 \%$; SLP: 8,0 vs. 5,6 meses, y SG: 14,1 vs. 10,3 meses en pacientes tratados con FOLFIRI \pm cetuximab, respectivamente). Aunque el pequeño tamaño muestral impide sacar conclusiones definitivas, parece que la presencia de mutaciones de BRAF tiene más valor pronóstico que predictivo. Se han observado resultados similares en el estudio CAIRO2, en el cual la presencia de mutaciones BRAF se asoció de manera significativa con la SLP y la SG, tanto en pacientes tratados con cetuximab como en los que no recibieron dicho anticuerpo ${ }^{42}$.

\section{Receptor del factor de crecimiento epidérmico}

Inicialmente, las terapias dirigidas frente a EGFR eran desarrolladas exclusivamente en tumores que expresaban EGFR en la superficie celular, detectado por técnicas de IHQ (85\% de los (CR). No obstante, con posterioridad se observó que no existía una buena correlación entre la expresión proteica de EGFR y la respuesta a estos fármacos. De hecho, se han documentado tasas de RG de hasta el $25 \%$ en tumores EGFRnegativos. Por otro lado, y al contrario de lo que ocurre en otras neoplasias, la existencia de mutaciones activantes de EGFR es excepcional en el CCR.

Otros factores que se han postulado como potenciales biomarcadores predictivos de respuesta a terapias antiEGFR incluyen la sobreexpresión de ligandos naturales del receptor, como la epirregulina y la amfirregulina ${ }^{44}$, determinados polimorfismos del ligando (EGF61A/G vs. EGF61A/A o EGF61G/G $)^{45}$, la amplificación del gen EGFR o la polisomía del cromosoma 7 (ambas circunstancias asociadas a un incremento en el número de copias del gen $)^{46}$. Así mismo, también se ha observado que existen polimorfismos de los receptores gamma Fc (Fc $\gamma \mathrm{R})$ de las células efectoras inmunes (FcyRlla-131H/H y/o FcyRIIla-158V/V) que se asocian con una mejor respuesta al tratamiento basado en cetuximab, incluso en tumores con mutaciones de KRAS. Esto apoyaría la hipótesis de que la citotoxicidad celular mediada por anticuerpos podría jugar un papel relevante en este contexto. No obstante, muchos de estos datos provienen de series pequeñas, retrospectivas, sin adecuados controles, lo cual no permite extraer conclusiones definitivas acerca de su utilidad clínica.

\section{Otras mutaciones}

La ruta PI3K-AKT-mTOR es otra de las principales vías efectoras de señalización intracelular que activa la estimulación del EGFR. Se han descrito mutaciones activadoras de PIK3CA en aproximadamente el $15 \%$ de los carcinomas de colon, fundamentalmente en el exón 9 (69\%) y en el exón 20 $(20 \%)^{38}$. Parece que únicamente las mutaciones del exón 20 se asocian con resultados clínicos inferiores en series no controladas de pacientes tratados con cetuximab, con tasas de RG de $0 \%$ vs. $37 \%$, SLP de 11,5 vs. 24 semanas y SG de 34 vs. 51 semanas en pacientes con PIK3CA mutado (exón 20) vs. no mutado, respectivamente ${ }^{38}$. No obstante, estos datos deben ser confirmados mediante estudios prospectivos que estén adecuadamente diseñados para ello.

Por otro lado, PTEN es un gen supresor tumoral que inhibe la vía de señalización PI3K/AKT. La pérdida de la función de PTEN mediante mutaciones, deleciones o silenciamiento epigenético conduce a la activación de esta ruta. Algunos estudios han observado una asociación significativa entre la pérdida de expresión de PTEN y una menor respuesta a los tratamientos anti-EGFR ${ }^{47,48}$. No obstante, otros autores han obtenido conclusiones discordantes. Esta disparidad de resultados puede ser debida tanto a la falta de estandarización de la técnica empleada para la detección de PTEN como a la complejidad de las interacciones intracelulares con otras rutas que pueden modular esta respuesta.

En base a estas premisas, este panel de expertos recomienda que: 
- El estado de KRAS debe ser determinado en todos los pacientes con CCR metastásico en los que se considere la administración de una terapia anti-EGFR, ya que esta terapia solo debe administrarse cuando no existan mutaciones en este gen (nivel de evidencia la).

- La determinación del estado de BRAF, EGFR, PI3K y PTEN en estos pacientes no debe realizarse de forma rutinaria, ya que no es necesaria para la toma de decisiones terapéuticas (nivel de evidencia llb para BRAF; nivel de evidencia IIIc para EGFR, PI3K y PTEN).

\section{Aspectos anatomopatológicos}

\section{Centros de referencia}

El estudio de los biomarcadores de susceptibilidad al CCR hereditario, así como de los factores biológicos que condicionan la predicción de la respuesta a la terapia administrada o la elección de un diseño terapéutico específico, requieren la participación de laboratorios reconocidos por su experiencia y acreditados por controles de calidad externos e internos.

Así, la situación ideal sería que fuera el propio laboratorio de anatomía patológica que custodia la muestra el que realice las técnicas IHQ o moleculares pertinentes. Si esto no fuera posible, la existencia de laboratorios de biología molecular adscritos a las fundaciones del propio hospital, a los servicios de oncología o al laboratorio central podría ser una solución alternativa ${ }^{49}$.

\section{El diagnóstico histológico certero como primer biomarcador}

Mientras que el primer diagnóstico histológico de un CCR se obtiene mediante el estudio de las biopsias endoscópicas obtenidas por fibrocolonoscopia, el diagnóstico definitivo se realiza a partir del estudio de la pieza de resección quirúrgica. Para garantizar el diagnóstico histológico de CCR con el material endoscópico es esencial que el tumor esté bien muestreado y que, como mínimo, haya 3 muestras representativas del tumor. Las biopsias muy superficiales de la lesión permiten observar la atipia citológica y la complejidad arquitectural glandular, que son características suficientes para reconocer un tumor epitelial maligno. Sin embargo, para emitir un diagnóstico de adenocarcinoma infiltrante es imprescindible observar la presencia de glándulas tumorales entre un estroma desmoplásico, para lo cual se precisa de biopsias de un tamaño suficiente. Además, la conveniencia de realizar estudios moleculares en el material tumoral endoscópico en determinadas ocasiones es otro de los motivos que justifica obtener una mínima cantidad adecuada de tumor biopsiado.

Por último, hay que recordar que el CCR no es una entidad monolítica, ya que además del adenocarcinoma convencional hay toda una serie de neoplasias primarias de estirpe variada (epitelial, estromal o neuroendocrina) con las que debe hacerse el diagnóstico diferencial mediante la clasificación de la Organización Mundial de la Salud (OMS). En estos casos, la realización de técnicas IHQ permite conocer el tipo celular de la neoplasia, ofreciendo la posibilidad de
Tabla 3 Descripción de la fase pre-analítica

Fijación de la muestra

Rápida (durante la primera hora tras su obtención)

Utilizar formol neutro tamponado al 10\% durante $<24 \mathrm{~h}$

De 6 a 12 h en muestras de biopsias endoscópicas

De 8 a 24 h en muestras quirúrgicas

Evitar fijadores basados en alcohol $\left(B 5^{\circledR}, P E N-F I X^{\circledR}\right)$ que contengan mercurio (BOUIN ${ }^{\circledR}$, ZENKER ${ }^{\circledR}$ ) o métodos de

fijación rápida mediante microondas

Procesamiento de la muestra

El procesamiento de la muestra se realiza siguiendo el protocolo estándar

hacer diagnósticos de certeza, siempre y cuando se disponga de material endoscópico suficiente ${ }^{50}$.

Desde que la muestra de tejido tumoral llega al servicio de anatomía patológica hasta que se emite el informe de resultados, se pueden establecer 3 fases que agrupan todos los procesos que se llevan a cabo, denominadas: a) fase pre-analítica, que incluye la fijación y el procesamiento de la muestra, pero también establece si existe indicación para llevar a cabo el estudio mutacional; b) fase analítica, que incluye la selección de la muestra y la técnica molecular más adecuada con sus controles correspondientes, y c) fase postanalítica, con la interpretación de los resultados y la emisión de un informe de diagnóstico molecular.

Todas estas etapas son fundamentales, y en cualquiera de ellas se pueden producir problemas que interfieren con la calidad de la determinación. El laboratorio que realice la determinación debe tener control sobre todos esos procesos $\mathrm{y}$, si es posible, hacerlo de manera integrada.

\section{Fase pre-analítica}

Las muestras endoscópicas deben fijarse una vez extraídas en formaldehído tamponado al $10 \%$, durante un tiempo no superior a las $24 \mathrm{~h}$ y de forma previa a su inclusión en parafina (tabla 3).

Es conveniente que las piezas de colectomía por tumor se remitan en fresco al servicio de anatomía patológica en el menor tiempo posible desde la extracción, a ser posible en menos de $30 \mathrm{~min}$. De esta manera se garantiza la integridad de los ácidos nucleicos, evitando su degradación por parte de las enzimas ribonucleasas (ARNasas). Se procederá entonces a la criopreservación del tejido tumoral y no tumoral para poder incluirlo en el banco de tumores y realizar los estudios moleculares necesarios, garantizando en todo momento el correcto manejo de la pieza quirúrgica. El tumor se fija en formaldehído tamponado al $10 \%$ durante $24-48 \mathrm{~h}$ y posteriormente se corta en secciones representativas del tumor que se incluyen en parafina. Es también conveniente preservar en parafina una muestra de la mucosa cólica sana, ya que permite el diagnóstico histológico de las lesiones precursoras y se dispone de material parafinado de tejido no tumoral del paciente. Además, las secciones representativas del tumor deben contener mucosa sana adyacente para poder descubrir la presencia de un pólipo previo sobre el 
que se ha podido desarrollar el carcinoma, así como de la zona de máxima infiltración local del tumor.

Los carcinomas son lesiones únicas, y todo el material que no se preserve, mediante congelación o inclusión en parafina, está destinado a desaparecer. Cabe, por tanto, ser consciente de ello e intentar preservar un número no inferior a 5 bloques del tumor y, si es posible, destinar una muestra del tejido tumoral y otra del tejido sano en parafina al banco de tumores. Además, es importante inspeccionar la mucosa sana alejada del tumor en busca de lesiones. La detección y el estudio histológico de lesiones polipoides diminutas pueden dar pistas para el diagnóstico de un síndrome de poliposis hereditaria. Por otro lado, los tipos histológicos mucinoso y medular, así como la presencia de un elevado infiltrado inflamatorio linfocitario intratumoral o peritumoral, son características típicas de los CCR asociados al síndrome de Lynch. En estos casos se debería estudiar la expresión IHQ de las proteínas de los genes reparadores del ADN (MLH1, MSH2, MSH6 y MPS2), o bien realizar el estudio de la MSI mediante la reacción en cadena de la polimerasa (PCR). Por último, la búsqueda rigurosa de los ganglios linfáticos que se encuentran inmersos en el tejido adiposo pericólico, a pesar de ser un quehacer tedioso, permite establecer una estadificación tumoral correcta. En la última edición de la clasificación internacional de TNM se considera recomendable la valoración histológica de 120 más ganglios linfáticos.

Por último, para que el resultado de las técnicas de biología molecular sea considerado válido, es imprescindible realizar una selección correcta de la muestra tumoral. Para ello es necesario que participe el patólogo. En cualquier caso, hay que tener en cuenta una serie de requerimientos indispensables, como que: a) es mejor extraer el ADN del tumor de la pieza de resección que de la biopsia endoscópica; b) se deben evitar las áreas con necrosis y con abundante inflamación, y c) se debe intentar microdisecar de forma manual la mayor porción posible de tumor, con la menor cantidad posible de tejido sano, para asegurar que la mayoría del ADN extraído pertenece a las células tumorales. En el caso de tumores sincrónicos, hay que recordar que se deben estudiar ambas neoplasias como tumores independientes ${ }^{51}$.

Aunque existe una buena correlación entre los resultados de mutaciones de KRAS obtenidos en el tumor primario y las metástasis, se recomienda efectuar los estudios moleculares también en el tejido metastásico, dado que las mutaciones pueden aparecer en ese tejido de novo $0^{52-54}$.

\section{Fase analítica}

En la actualidad solo se considera útil conocer el estado de las mutaciones de KRAS para seleccionar un tratamiento con anticuerpos monoclonales anti-EGFR. Sin embargo, solo un tercio de los pacientes con KRAS no mutado responden al tratamiento. Por ello, se están haciendo importantes esfuerzos para descubrir nuevas dianas terapéuticas que ofrezcan alternativas de tratamiento al subgrupo de pacientes no respondedores. Las vías de señalización en las que más biomarcadores se están estudiando son EGFR/Ras/Raf/Mek/Erk (MAP cinasa) y la PTEN/PI3K/AKT.
Determinación de la inestabilidad de microsatélites

El estudio de la vía reparadora MMR se utiliza fundamentalmente para identificar a los pacientes con síndrome de Lynch. Se caracteriza por mutaciones en la línea germinal de MLH1, MSH2, MSH6 y, menos frecuentemente, en PMS2 o EPCAM. Además, los pacientes con tumores MMR positivos tienen mejor pronóstico.

En este sentido, es recomendable que el estudio de la vía reparadora MMR se realice en todos los pacientes con CCR. Para ello, se debe realizar el primer lugar el estudio de todos los pacientes por IHQ. En el caso de que la expresión no sea concluyente y existan criterios clínicos o anatomopatológicos definidos de alta sospecha de CCR familiar, es necesario además realizar el estudio de la MSI.

El estudio por IHQ de MLH1, MSH2, MSH6, PMS2 permite identificar mediante las proteínas que codifican qué gen está probablemente alterado. Un tumor muestra «expresión conservada» si se observa la tinción nuclear de las células tumorales; «pérdida de expresión» si se observa ausencia de tinción nuclear en las células tumorales, con la presencia de control interno positivo (linfocitos intratumorales, células del estroma, mucosa no tumoral), y se considera «no valorable» cuando la ausencia de expresión no se acompaña de un control interno positivo. Así, si existe pérdida de la expresión de $\mathrm{MLH} 1$, pueden existir otros marcadores complementarios, como la mutación de BRAF-V600E o la metilación del promotor MLH1. Casi todos los casos en los que se observa la hipermetilación del promotor de MLH1 son esporádicos. Excepcionalmente, también se han descrito metilaciones en la línea germinal.

Por el contrario, la determinación de la MSI se realiza sobre ADN tumoral. Actualmente se tiende a utilizar un panel de 5 marcadores mononucleótidos, comercializados en forma de ensayo, ya que realiza una determinación con mayor sensibilidad que el panel de Bethesda y no precisa la comparación con ADN constitucional. Un tumor se considera inestable si presenta, al menos, 2 marcadores alterados.

Para interpretar los resultados, se debe tener en cuenta lo siguiente:

- En el $90 \%$ de los casos, la pérdida de expresión de MLH1 y PMS2 se considera un evento esporádico. Para identificarlo como tal, se puede realizar además el estudio de BRAF y la determinación de la metilación de MLH1.

- La pérdida de expresión de MSH6 es un evento secundario, ya que MSH6 tiene una secuencia microsatélite en la región codificante.

- La pérdida de expresión de MSH2 y MSH6, de MSH6 aislada, de PMS2 aislada o la existencia de un tumor inestable sin pérdida de expresión IHQ se asocia con mucha frecuencia a la existencia de un síndrome de Lynch.

- Si se observa un tumor estable con pérdida de expresión IHQ, se debe repetir la extracción de ADN y el estudio IHQ para confirmar la discordancia.

- Otros patrones diferentes a los ya descritos son muy raros y deben ser tratados de forma individualizada.

\section{Determinación de KRAS}

La indicación para la determinación de KRAS puede venir tanto del oncólogo médico como de grupos multidisciplinares que establezcan algoritmos de actuación. Cuando 
exista esa indicación, el patólogo debe llevar a cabo la determinación mutacional, tanto cuando el paciente tenga enfermedad avanzada, como cuando incluso se realice el diagnóstico histopatológico inicial del tumor.

La determinación del estado mutacional de KRAS es importante porque: a) ayuda a optimizar la selección de candidatos a recibir terapias basadas en inhibidores específicos, aunque se deba tener en cuenta que dentro de las vías de señalización existen otros factores que pueden estar también alterados, induciendo la proliferación celular; b) las mutaciones de KRAS que se asocian a una activación constitutiva confieren resistencia a los tratamientos con anticuerpos monoclonales dirigidos contra EGFR, y c) en la actualidad, tanto la Agencia de Alimentos y Medicamentos estadounidense (FDA) como la Agencia Europea de Medicamentos (EMA) requieren el estudio mutacional de KRAS en CCR antes de administrar anticuerpos monoclonales contra EGFR.

En cualquier caso, existen algunas situaciones en las que se puede rechazar la determinación de mutaciones de KRAS en pacientes con CCR; estas incluyen: a) la ausencia de confirmación histológica de carcinoma infiltrante por parte de un patólogo; b) que la muestra no alcance los requerimientos de calidad recomendados en cuanto a prefijación, fijación, escasa representación tumoral en la muestra, baja calidad del ADN, etc.; c) que no se consiga la calidad requerida durante las fases analítica y postanalítica (p. ej., por resultados insatisfactorios en los controles internos), y d) que se obtengan resultados negativos con muestras insuficientes 0 inadecuadas, es decir, por debajo del umbral de sensibilidad que requiere la técnica empleada.

Para la determinación del estado mutacional de KRAS es importante tener en cuenta las recomendaciones existentes $^{55}$, tanto para la fase pre-analítica como para la fase analítica, así como los métodos empleados en cada una de ellas. En la fase analítica, para el estudio de mutaciones de KRAS y de otras alteraciones moleculares es importante en primer lugar la selección de la muestra. En el caso de KRAS, dada la alta concordancia que existe entre las mutaciones del tumor primario y las mutaciones de las metástasis, se puede elegir la muestra de tumor que sea más representativa, si bien pueden aparecer mutaciones de novo en el tejido metastásico ${ }^{52-54}$. Dicha muestra puede proceder tanto de la pieza quirúrgica como de una biopsia endoscópica o de una citología mediante punción aspiración con aguja fina de las lesiones metastásicas. Un tema importante, y no cerrado, es el porcentaje de tumor que debe tener la muestra para su estudio molecular. Con los avances continuos en los protocolos de diagnóstico molecular, en los que se va incrementando la sensibilidad diagnóstica, el porcentaje de células tumorales necesario para el diagnóstico molecular es cada vez menor. No obstante, se recomienda realizar el diagnóstico en bloques representativos, con un mínimo de 6 a 10 cortes de unas 5 micras cada uno. En este sentido, se recomienda seleccionar el bloque con mayor porcentaje tumoral y/o marcar con un rotulador las áreas de mayor concentración tumoral viable, reflejar el porcentaje de necrosis observado en la muestra elegida y realizar posteriormente, si fuera necesario, una macrodisección de las secciones completas con una aguja histológica y/o un bisturí o una microdisección en el caso de que sean lesiones mínimas con un porcentaje de células tumorales muy escaso.
Los métodos y técnicas moleculares que se utilizan para determinar las mutaciones de KRAS son los mismos que para cualquier estudio de patología molecular. En este sentido, se pueden utilizar métodos de secuenciación directa, como el método de Sanger, con sus limitaciones inherentes. Es un método de alta especificidad pero de baja sensibilidad. Para realizarlo, se requiere habitualmente una mayor cantidad de ADN mutado tumoral, con una sensibilidad en torno al $25 \%$. En línea con métodos de secuenciación directa, hoy en día se está implementando la pirosecuenciación, que requiere un pirosecuenciador pero que tiene una sensibilidad más alta, en torno al 5-10\% del ADN mutado. Sin embargo, los métodos que se utilizan con mayor frecuencia son los métodos basados en la PCR cuantitativa a tiempo real, en la que hay diversos protocolos y aproximaciones metodológicas. En primer lugar, la técnica de TaqmanPCR, que es un método ideal para detectar mutaciones específicas y con una alta sensibilidad, en torno al 5-10\%. También basado en la PCR cuantitativa a tiempo real, el método de Scorpions-ARMS detecta solo mutaciones específicas, con una alta sensibilidad, incluso menor del $1 \%$ del ADN mutado.

En el caso de que se requieran técnicas para el enriquecimiento del alelo mutado, estos ya son métodos y técnicas que requieren una mayor capacitación técnica y experiencia en los laboratorios que las realicen. Así, hay métodos que enriquecen las técnicas de PCR ${ }^{55}$, como el PNA-LNAPCR CLAMP, que tiene una sensibilidad incluso de hasta el $0,1 \%$ del ADN mutado, o el COLD-PCR, con una sensibilidad incluso menor del $0,1 \%$.

Por último, existen otros métodos basados en mutaciones que generan cambios en dianas de restricción para determinadas enzimas que podrían realizarse, como los basados en la cromatografía líquida de alta resolución o la manometría de alta resolución o Melting de alta resolución que, aunque es un método que está en fase de desarrollo incipiente, se cree que puede tener un gran desarrollo a corto y medio plazo.

\section{Determinación de BRAF}

La mutación V600E es el cambio más frecuente del gen BRAF en CCR y se puede estudiar de forma sencilla mediante secuenciación.

\section{Determinación de EGFR}

Para estudiar la expresión de EGFR por IHQ existen en el mercado distintos anticuerpos que reconocen diferentes epítopos del receptor, y no hay unanimidad ni consenso en cuanto a su utilización, al protocolo de realización de la técnica ni a la valoración de los resultados. Por ello, quizá los datos de la literatura son contradictorios y es difícil extraer conclusiones. La expresión tumoral de EGFR mediante IHQ es heterogénea y más intensa en el frente profundo de invasión del tumor ${ }^{56}$, si bien hay autores que correlacionan la tinción de máxima intensidad $(3+)$ con la amplificación del gen mediante técnicas de hibridación cromogénica in situ ${ }^{57}$. La detección IHQ de la proteína fosforilada o activada no aporta mejores resultados sobre la detección de la expresión de $\mathrm{EGFR}^{58}$.

Actualmente no se utiliza la determinación IHQ de EGFR para la selección de los pacientes con CCR metastásico tributarios al tratamiento con cetuximab ${ }^{59}$. 
Determinación de otras mutaciones

La falta de expresión de PTEN por técnicas de IHQ se ha correlacionado con la falta de respuesta a cetuximab ${ }^{60-62}$. Sin embargo, otros autores consideran la pérdida de expresión de PTEN como un indicador de mal pronóstico ${ }^{47,63,64}$. La existencia de resultados dispares se debe en parte a problemas con la técnica de IHQ, a los patrones de positividad (citoplasmática vs. nuclear) y a los distintos anticuerpos empleados ${ }^{65}$.

En cuanto a la determinación de mutaciones de PI3K, según se desprende de un metaanálisis reciente, las mutaciones del exón 20 , más que las del exón 9 , pueden ser un marcador de resistencia al tratamiento con anticuerpos monoclonales anti-EGFR en el CCR avanzado con KRAS nativo ${ }^{66}$.

Por último, existen en el mercado diferentes anticuerpos para detectar p-AKT mediante IHQ, y no hay unanimidad ni consenso en cuanto a su utilización ${ }^{67}$.

\section{Fase postanalítica}

Los informes emitidos deben contener los datos anatomopatológicos necesarios para confeccionar el TNM del tumor y aportar los datos moleculares que condicionan el tratamiento. Existen protocolos de consenso elaborados por las distintas asociaciones de patólogos que revisan de forma periódica la información que debe existir en los informes anatomopatológicos y los actualizan en base a los cambios que se producen en la clasificación $T_{N M}^{68,69}$. Así, en la séptima edición de la clasificación TNM destacan las siguientes novedades $^{70}$ :

- La invasión tumoral de las estructuras vasculares, ya sean vasos linfáticos o venas, se describe bajo una única categoría de invasión angiolinfática.

- Los depósitos tumorales satélites son nódulos o grupos de células tumorales que se encuentran en el tejido adiposo, donde están los ganglios linfáticos regionales de drenaje del carcinoma primario.

- Si el depósito tumoral tiene un margen redondeado, debe considerarse un ganglio linfático totalmente infiltrado por el tumor. Si en el estudio microscópico se evidencian restos del ganglio linfático, también se considerará que existe un ganglio linfático metastásico. En ambas circunstancias, estas lesiones se añadirán al cómputo final de los ganglios metastásicos que configuran el $\mathrm{pN}$.

- Sin embargo, si el depósito tumoral tiene forma irregular y no se evidencia ningún resto de ganglio linfático, se considerará que se trata de un crecimiento satélite del tumor primario o una invasión venosa con infiltración extravascular. En ambas circunstancias, tanto si hay uno o varios, se reportará como un depósito tumoral en la categoría pN1c en los carcinomas sin ganglios linfáticos metastásicos con pT1 o pT2.

- La presencia de tumor en el peritoneo se considerará como metástasis (M1b).

Se recomienda incluir en el informe los resultados de las técnicas IHQ acerca de la expresión de las proteínas de los genes reparadores del ADN (MLH1, MSH2, MSH6 y PMS2), de los marcadores moleculares de MSI y de las mutaciones de los genes KRAS y $B R A F^{68}$.

\section{Controles de calidad internos y externos}

Se recomienda que los laboratorios que realicen la determinación de los biomarcadores, tanto IHQ como moleculares, participen en programas de control de calidad, como el implantado por la SEAP.

Debería ser potestativo de la autoridad sanitaria de cada comunidad autónoma establecer las exigencias de acreditación y certificación de los laboratorios. En el caso de que se consensúe la realización de estas técnicas en determinados centros de referencia en función de su nivel de acreditación y certificación, debería concederse un plazo de tiempo suficiente para que los centros interesados en realizarlas puedan lograr la acreditación y la certificación exigidas.

\section{Aspectos comunes}

\section{Tiempos recomendados y aceptables}

El tiempo de entrega de los resultados depende de: a) el tiempo desde la petición de la muestra hasta la obtención de la misma; b) el tiempo de envío de la muestra al laboratorio donde se realizan las pruebas; c) el tiempo desde la recepción de la muestra en el laboratorio hasta la obtención y emisión del resultado, y d) el tiempo desde el envío del resultado hasta su recepción por el médico peticionario. Dada la complejidad de los procedimientos y la participación de diferentes profesionales en él, es necesario establecer un flujo de trabajo en cada centro que permita la optimización del proceso de análisis.

Teniendo en cuenta la relevancia de la determinación del estado mutacional de KRAS en la toma de decisiones de los pacientes con CCR metastásico, el tiempo total para contar con el resultado de este estudio debe situarse en torno a los 7 días laborables.

Además sería aconsejable que en los centros de referencia de CCR existiera una unidad de consejo genético o una clínica de alto riesgo de CCR capaz de integrar los resultados, de tomar decisiones terapéuticas y de manejo del paciente, así como de decidir la realización de pruebas adicionales ante los resultados moleculares obtenidos.

\section{Implicaciones legales}

El manejo de la información genética tiene una gran repercusión desde el punto de vista terapéutico y pronóstico. Sin embargo, también tiene implicaciones legales y éticas que es obligado conocer y que persiguen respetar la confidencialidad y la autonomía de los pacientes.

A este respecto, y entre otras leyes aplicables, la Ley de Investigación Biomédica de 3 de julio de 2007 y el Real Decreto 1716/2011 de la misma, publicado el 2 de diciembre de 2011, que será efectivo el 2 de junio de 2012, aborda el tema del manejo de este tipo de información ${ }^{71}$. En esta ley existen algunos aspectos eminentemente prácticos que conviene resaltar en este documento de consenso, sobre todo en un área tan sensible como es el cáncer hereditario. Como 
se ha comentado con anterioridad, la realización de algunos estudios moleculares puede ayudar a identificar qué pacientes con CCR tienen un patrón hereditario, como el estudio de la MSI o la expresión de proteínas de algunos genes reparadores.

Desde un punto de vista legal, se debe informar a los pacientes a los que se les va a hacer este tipo de estudios que un resultado positivo puede implicar un incremento del riesgo a desarrollar no sólo CCR, sino algún otro tumor asociado al síndrome de Lynch, como puede ser el cáncer de endometrio. Por otro lado, esta información genética afecta a otros miembros de la familia, por lo que pueden verse implicados en el proceso. Por todos estos motivos, es necesario que los pacientes firmen un consentimiento informado autorizando la realización de estudios genéticos de la línea germinal. Además, se les debe ofrecer la posibilidad de recibir un asesoramiento genético adecuado en función del resultado.

Entre los aspectos que debe recoger el consentimiento informado para este tipo de estudios se incluyen: a) la finalidad del estudio; b) el lugar de realización y destino de la muestra biológica al término del mismo; c) las personas que tendrán acceso al resultado; d) la advertencia sobre la posibilidad de hallazgos inesperados; e) la implicación que puede tener para sus familiares, y f) el compromiso de suministrar consejo genético. Si el paciente ideal para realizar este tipo de estudios ya ha fallecido, también se podrán realizar siempre y cuando no haya una prohibición expresa del mismo y exista un beneficio potencial para sus familiares biológicos, obviamente, con su autorización previa.

Hay que tener en cuenta que aunque el paciente haya dado su consentimiento informado previo, este puede ser revocado en el momento en el que el sujeto así lo desee. Sin embargo, cuando esta información sea necesaria para evitar un grave perjuicio para la salud de los familiares biológicos, se podrá informar a los afectados o a al representante legalmente autorizado.

Los resultados de los estudios realizados se deben conservar durante un período mínimo de 5 años. Si no mediase solicitud del interesado, los datos se conservarán durante el plazo que sea necesario para preservar la salud del sujeto o de terceras personas relacionadas.

Por último, siempre que se lleve a cabo un estudio genético con fines sanitarios, es preciso garantizar al interesado un asesoramiento genético adecuado. En este proceso se abordarán temas relacionados con el riesgo de desarrollar cáncer, tanto para él como para su descendencia, además de medidas de control de ese riesgo, aspectos reproductivos y manejo psicológico.

\section{Conclusiones}

El CCR representa un modelo ideal para el estudio de la patogénesis molecular del cáncer, debido a la facilidad que existe para obtener la biopsia tumoral y a los cambios genéticos específicos que se producen en cada una de las etapas de su evolución. Esta situación ha llevado a la identificación de biomarcadores pronósticos y predictivos que ayudan al manejo clínico de esta patología, tanto en la fase diagnóstica como terapéutica.
La necesidad de realizar una determinación adecuada de biomarcadores en cada una de las fases clínicas del CCR (consejo genético, CCR localizado operado radicalmente y CCR metastásico) ha motivado la génesis de esta guía, en la que se revisa el nivel de evidencia que tiene la determinación de cada uno de estos biomarcadores. Otros aspectos importantes de este consenso son la evaluación de los requisitos organizativos y los controles de calidad que deben existir para determinar estos biomarcadores, y que afectan especialmente al servicio de anatomía patológica, para conseguir un diagnóstico riguroso en el menor tiempo posible, así como las implicaciones legales existentes para evaluar determinados biomarcadores.

En lo que concierne al consejo genético, la mayoría de las neoplasias colorrectales se producen por inactivación del gen APC, ya sea por mutación esporádica o mutación de la línea germinal, y en las que no se produce MSI. Por esta razón, los pacientes con alto riesgo de desarrollar CCR pueden ser identificados mediante la realización de pruebas genéticas para detectar mutaciones específicas de la línea germinal.

En el CCR localizado, la MSI es un marcador de susceptibilidad al CCR hereditario, pero también es un factor predictivo de gran relevancia para decidir el tratamiento adyuvante del paciente con estadioll. Está bien establecido que su presencia confiere mejor pronóstico. Sin embargo, el valor predictivo de resistencia al 5-FU es más controvertido. Por otro lado, aunque las firmas de expresión genética ColoPrint ${ }^{\circledR}$ y Oncotype $D x^{\circledR}$ han demostrado tener valor pronóstico, no existe todavía consenso sobre su uso en la práctica clínica.

En cuanto al CCR metastásico, la determinación del estado mutacional del oncogén KRAS, que está presente en el $40 \%$ de los pacientes con CCR, es obligatoria antes de administrar tratamiento con anti-EGFR, como cetuximab y panitumumab, dado el valor predictivo negativo de respuesta que tiene.

Las recomendaciones que se establecen en este consenso se circunscriben a la práctica clínica asistencial, aunque también se evalúan otros biomarcadores que pueden formar parte de la rutina clínica a corto plazo, si se confirma su valor predictivo, como son las mutaciones de BRAF, EGFR, $P I 3 K, P T E N$ y $A K T$. Finalmente, sería aconsejable que cuando se realicen estudios moleculares existiera una unidad de consejo genético en el propio centro o en el centro de referencia, con capacidad de integrar la información y asesorar a los pacientes afectados y a sus familiares.

Este documento es el resultado de un trabajo multidisciplinar y consensuado de oncólogos y anatomopatólogos sobre el uso racional de biomarcadores en el CCR, así como sus métodos de determinación, que sienta las bases para un futuro en el que se prevé un importante desarrollo y un aumento de la complejidad, y que puede conducir al tratamiento personalizado del paciente con terapias más eficaces.

\section{Responsabilidades éticas}

Protección de personas y animales. Los autores declaran que para esta investigación no se han realizado experimentos en seres humanos ni en animales. 
Confidencialidad de los datos. Los autores declaran que en este artículo no aparecen datos de pacientes.

Derecho a la privacidad y consentimiento informado. Los autores declaran que en este artículo no aparecen datos de pacientes.

\section{Financiación}

La SEOM agradece el apoyo financiero de este proyecto mediante becas sin restricción de Amgen S.A., Merck S.L., Roche Farma (España) y Sanofi.

\section{Conflicto de intereses}

Los autores declaran que, en el momento de la redacción y revisión del texto, desconocían el nombre de los laboratorios que han apoyado económicamente este proyecto, por lo que este apoyo no ha influido en el contenido de este artículo.

\section{Agradecimientos}

Beatriz Gil-Alberdi, de HealthCo (Madrid, España), ha proporcionado asistencia editorial para el desarrollo de este manuscrito. Los miembros del Grupo de Trabajo en Biomarcadores SEOM-SEAP son R. Colomer, P. García-Alfonso, P. Garrido, A. Ariza, E. de Álava y J. Palacios.

\section{Bibliografía}

1. American Gastroenterological Association medical position statement: hereditary colorectal cancer and genetic testing. Gastroenterology. 2001;121:195-7.

2. Vasen HF, Watson P, Mecklin JP, Lynch HT. New clinical criteria for hereditary nonpolyposis colorectal cancer (HNPCC, Lynch syndrome) proposed by the International Collaborative group on HNPCC. Gastroenterology. 1999;116:1453-6.

3. Lynch HT, de la Chapelle A. Hereditary colorectal cancer. N Engl J Med. 2003;348:919-32.

4. Umar A, Boland CR, Terdiman JP, Syngal S, de la Chapelle A, Rüschoff J, et al. Revised Bethesda Guidelines for hereditary nonpolyposis colorectal cancer (Lynch syndrome) and microsatellite instability. J Natl Cancer Inst. 2004;96:261-8.

5. Balmana J, Stockwell DH, Steyerberg EW, Stoffel EM, Deffenbaugh AM, Reid JE, et al. Prediction of MLH1 and MSH2 mutations in Lynch syndrome. JAMA. 2006;296:1469-78.

6. Popat S, Houlston RS. A systematic review and meta-analysis of the relationship between chromosome 18q genotype, DCC status and colorectal cancer prognosis. Eur J Cancer. 2005;41:2060-70.

7. Shibata D, Reale MA, Lavin P, Silverman M, Fearon ER, Steele Jr $\mathrm{G}$, et al. The DCC protein and prognosis in colorectal cancer. $\mathrm{N}$ Engl J Med. 1996;335:1727-32.

8. Alazzouzi H, Alhopuro P, Salovaara R, Sammalkorpi $H$, Järvinen $\mathrm{H}$, Mecklin JP, et al. SMAD4 as a prognostic marker in colorectal cancer. Clin Cancer Res. 2005;11:2606-11.

9. Roth AD, Tejpar S, Yan P, Fiocca R, Dietrich D, Delorenzi M, et al. Stage-specific prognostic value of molecular markers in colon cancer: Results of the translational study on the PETACC 3-EORTC 40993-SAKK 60-00 trial. ASCO Meeting Abstracts. 2009;27:4002.

10. Ogino S, Nosho K, Kirkner GJ, Shima K, Irahara N, Kure S, et al. PIK3CA mutation is associated with poor prognosis among patients with curatively resected colon cancer. J Clin Oncol. 2009;27:1477-84.

11. Popat S, Hubner R, Houlston RS. Systematic review of microsatellite instability and colorectal cancer prognosis. J Clin Oncol. 2005;23:609-18.

12. Sargent DJ, Marsoni S, Monges G, Thibodeau SN, Labianca R, Hamilton SR, et al. Defective mismatch repair as a predictive marker for lack of efficacy of fluorouracil-based adjuvant therapy in colon cancer. J Clin Oncol. 2010;28:3219-26.

13. Hutchins G, Southward K, Handley K, Magill L, Beaumont C, Stahlschmidt J, et al. Value of mismatch repair, KRAS, and BRAF mutations in predicting recurrence and benefits from chemotherapy in colorectal cancer. J Clin Oncol. 2011;29:1261-70.

14. Sinicrope FA, Foster NR, Thibodeau SN, Marsoni S, Monges G, Labianca R, et al. DNA mismatch repair status and colon cancer recurrence and survival in clinical trials of 5-fluorouracil-based adjuvant therapy. J Natl Cancer Inst. 2011;103:863-75.

15. Tejpar S, Saridaki Z, Delorenzi M, Bosman F, Roth AD. MicrosateIlite instability, prognosis and drug sensitivity of stage II and III colorectal cancer: more complexity to the puzzle. J Natl Cancer Inst. 2011;103:841-4.

16. Bertucci F, Salas S, Eysteries S, Nasser V, Finetti P, Ginestier C, et al. Gene expression profiling of colon cancer by DNA microarrays and correlation with histoclinical parameters. Oncogene. 2004;23:1377-91.

17. Wang $Y$, Jatkoe T, Zhang $Y$, Mutch MG, Talantov D, Jiang J, et al. Gene expression profiles and molecular markers to predict recurrence of Dukes' B colon cancer. J Clin Oncol. 2004;22:1564-71.

18. Komuro K, Tada M, Tamoto E, Kawakami A, Matsunaga A, Teramoto K, et al. Right- and left-sided colorectal cancers display distinct expression profiles and the anatomical stratification allows a high accuracy prediction of lymph node metastasis. J Surg Res. 2005;124:216-24.

19. Eschrich S, Yang I, Bloom G, Kwong KY, Boulware D, Cantor A, et al. Molecular staging for survival prediction of colorectal cancer patients. J Clin Oncol. 2005;23:3526-35.

20. Croner RS, Peters A, Brueckl WM, Matzel KE, Klein-Hitpass L, Brabletz $\mathrm{T}$, et al. Microarray versus conventional prediction of lymph node metastasis in colorectal carcinoma. Cancer. 2005;104:395-404.

21. Barrier A, Boelle PY, Roser F, Gregg J, Tse C, Brault D, et al. Stage II colon cancer prognosis prediction by tumor gene expression profiling. J Clin Oncol. 2006;24:4685-91.

22. Barrier A, Roser F, Boelle PY, Franc B, Tse C, Brault D, et al. Prognosis of stage Il colon cancer by non-neoplastic mucosa gene expression profiling. Oncogene. 2007;26:2642-8.

23. Lin YH, Friederichs J, Black MA, Mages J, Rosenberg R, Guilford PJ, et al. Multiple gene expression classifiers from different array platforms predict poor prognosis of colorectal cancer. Clin Cancer Res. 2007;13:498-507.

24. Vendrell E, Ribas M, Valls J, Solé X, Grau M, Moreno V, et al. Genomic and transcriptomic prognostic factors in RO Dukes $\mathrm{B}$ and $\mathrm{C}$ colorectal cancer patients. Int J Oncol. 2007;30:1099-107.

25. O'Connell MJ, Lavery I, Yothers G, Paik S, Clark-Langone KM, Lopatin $M$, et al. Relationship between tumor gene expression and recurrence in four independent studies of patients with stage II/III colon cancer treated with surgery alone or surgery plus adjuvant fluorouracil plus leucovorin. J Clin Oncol. 2010;28:3937-44.

26. Gray RG, Quirke P, Handley K, Paik S, Clark-Langone KM, Lopatin M, et al. Validation Study of a Quantitative Multigene Reverse Transcriptase-Polymerase Chain Reaction Assay for Assessment of Recurrence Risk in Patients With Stage II Colon Cancer. J Clin Oncol. 2011;29:4611-9.

27. Glas AM, Roepman P, Salazar R, Capella G, Moreno V, Westerga J, et al. Development and validation of a robust prognostic and 
predictive signature for colorectal cancer (CRC) patients. ASCO Meeting Abstracts. 2009;27:4036.

28. Salazar R, Roepman P, Capella G, Moreno V, Simon I, Dreezen C, et al. Gene expression signature to improve prognosis prediction of stage II and III colorectal cancer. J Clin Oncol. 2011;29:17-24.

29. Rosenberg R, Maak M, Simon I, Nitsche U, Schuster T, Kuenzli B, et al. Independent validation of a prognostic genomic profile (ColoPrint) for stage II colon cancer (CC) patients. ASCO Meeting Abstracts. 2009;29:358.

30. Kennedy RD, Bylesjo M, Kerr P, Davison T, Black JM, Kay EW, et al. (2011) Development and Independent Validation of a Prognostic Assay for Stage II Colon Cancer Using Formalin-Fixed Paraffin-Embedded Tissue. J Clin Oncol. 2011;29:4620-6.

31. Roth AD, Tejpar S, Delorenzi M, Yan P, Fiocca R, Klingbiel D, et al. Prognostic role of KRAS and BRAF in stage II and III resected colon cancer: results of the translational study on the PETACC-3, EORTC 40993, SAKK 60-00 trial. J Clin Oncol. 2010;28:466-74.

32. Van Cutsem E, Kohne $\mathrm{CH}$, Hitre E, Zaluski J, Chang Chien CR, Makhson A, et al. Cetuximab and chemotherapy as initial treatment for metastatic colorectal cancer. N Engl J Med. 2009;360:1408-17.

33. Van Cutsem E, Kohne CH, Lang I, Folprecht G, Nowacki MP, Cascinu $\mathrm{S}$, et al. Cetuximab plus irinotecan, fluorouracil, and leucovorin as first-line treatment for metastatic colorectal cancer: updated analysis of overall survival according to tumor KRAS and BRAF mutation status. J Clin Oncol. 2011;29: 2011-9.

34. Bokemeyer C, Bondarenko I, Hartmann JT, de Braud F, Schuch G, Zubel A, et al. Efficacy according to biomarker status of cetuximab plus FOLFOX-4 as first-line treatment for metastatic colorectal cancer: the OPUS study. Ann Oncol. 2011;22:1535-46.

35. Bokemeyer C, Bondarenko I, Makhson A, Hartmann JT, Aparicio J, de Braud F, et al. Fluorouracil, leucovorin, and oxaliplatin with and without cetuximab in the first-line treatment of metastatic colorectal cancer. J Clin Oncol. 2009;27:663-71.

36. Folprecht G, Gruenberger T, Bechstein WO, Raab HR, Lordick F, Hartmann JT, et al. Tumour response and secondary resectability of colorectal liver metastases following neoadjuvant chemotherapy with cetuximab: the CELIM randomised phase 2 trial. Lancet Oncol. 2010;11:38-47.

37. Maughan TS, Adams RA, Smith CG, Meade AM, Seymour MT, Wilson RH, et al. Addition of cetuximab to oxaliplatin-based first-line combination chemotherapy for treatment of advanced colorectal cancer: results of the randomised phase 3 MRC COIN trial. Lancet. 2011;377:2103-14.

38. De Roock W, Claes B, Bernasconi D, De Schutter J, Biesmans B, Fountzilas $G$, et al. Effects of KRAS, BRAF, NRAS, and PIK3CA mutations on the efficacy of cetuximab plus chemotherapy in chemotherapy-refractory metastatic colorectal cancer: a retrospective consortium analysis. Lancet Oncol. 2010;11:753-62.

39. De Roock W, Jonker DJ, Di Nicolantonio F, Sartore-Bianchi A, Tu D, Siena S, et al. Association of KRAS p.G13D mutation with outcome in patients with chemotherapy-refractory metastatic colorectal cancer treated with cetuximab. JAMA. 2010;304:1812-20.

40. Douillard JY, Siena S, Cassidy J, Tabernero J, Burkes R, Barugel M, et al. Randomized, phase III trial of panitumumab with infusional fluorouracil, leucovorin, and oxaliplatin (FOLFOX4) versus FOLFOX4 alone as first-line treatment in patients with previously untreated metastatic colorectal cancer: the PRIME study. J Clin Oncol. 2010;28:4697-705.

41. Douillard J, Siena S, Cassidy J, Tabernero J, Burkes RL, Barugel ME, et al. Final results from PRIME: Randomized phase III study of panitumumab (pmab) with FOLFOX4 for first line metastatic colorectal cancer (mCRC). ASCO Meeting Abstracts. 2011;29:3510.
42. Knijn N, Mekenkamp LJ, Klomp M, Vink-Börger ME, Tol J, Teerenstra S, et al. KRAS mutation analysis: a comparison between primary tumours and matched liver metastases in 305 colorectal cancer patients. Br J Cancer. 2011;104:1020-6.

43. Richman SD, Seymour MT, Chambers P, Elliott F, Daly CL, Meade AM, et al. KRAS and BRAF mutations in advanced colorectal cancer are associated with poor prognosis but do not preclude benefit from oxaliplatin or irinotecan: results from the MRC FOCUS trial. J Clin Oncol. 2009;27:5931-7.

44. Khambata-Ford S, Garrett CR, Meropol NJ, Basik M, Harbison CT, $\mathrm{Wu} \mathrm{S}$, et al. Expression of epiregulin and amphiregulin and $\mathrm{K}$-ras mutation status predict disease control in metastatic colorectal cancer patients treated with cetuximab. J Clin Oncol. 2007;25:3230-7.

45. Spindler KL, Andersen RF, Jensen LH, Jensen LH, Ploen J, Jakobsen A. EGF61A>G polymorphism as predictive marker of clinical outcome to first-line capecitabine and oxaliplatin in metastatic colorectal cancer. Ann Oncol. 2010;21:535-9.

46. Moroni M, Veronese S, Benvenuti S, Marrapese G, SartoreBianchi A, Di Nicolantonio F, et al. Gene copy number for epidermal growth factor receptor (EGFR) and clinical response to antiEGFR treatment in colorectal cancer: a cohort study. Lancet Oncol. 2005;6:279-86.

47. Laurent-Puig P, Cayre A, Manceau G, Buc E, Bachet JB, Lecomte T, et al. Analysis of PTEN, BRAF, and EGFR status in determining benefit from cetuximab therapy in wild-type KRAS metastatic colon cancer. J Clin Oncol. 2009;27:5924-30.

48. Negri FV, Bozzetti C, Lagrasta CA, Crafa P, Bonasoni MP, Camisa R, et al. PTEN status in advanced colorectal cancer treated with cetuximab. Br J Cancer. 2010;102:162-4.

49. Libro Blanco de la Anatomía Patológica en España. Recursos, calidad e impacto de la Patología en España. $2^{a}$ ed. Sociedad Española de Anatomía Patológica; 2009 (Supl., 2011).

50. Hamilton SR, Bosman FT, Boffetta P, Ilyas M, Morreau H, Nakamura SI, et al. Carcinoma of the colon and rectum. En: Bosman FT, Carneiro F, Hruban RH, Theise ND, editores. WHO classification of the tumours of the digestive System. Lyon: International Agency for research on cancer; 2010. p. 135-136.

51. Balschun K, Haag J, Wenke AK, von Schönfels W, Schwarz NT, Röcken C. KRAS, NRAS, PIK3CA exon 20, and BRAF genotypes in synchronous and metachronous primary colorectal cancers diagnostic and therapeutic implications. J Mol Diagn. 2011;13:436-45.

52. Bouchahda M, Karaboue A, Saffroy R, Innominato P, Gorden L, Guettier $C$, et al. Acquired KRAS mutations during progression of colorectal cancer metastases: possible implications for therapy and prognosis. Cancer Chemother Pharmacol. 2010;66:605-9.

53. Italiano A, Hostein I, Soubeyran I, Fabas T, Benchimol D, Evrard S, et al. KRAS and BRAF mutational status in primary colorectal tumors and related metastatic sites: biological and clinical implications. Ann Surg Oncol. 2010;17:1429-34.

54. Mariani P, Lae M, Degeorges A, Cacheux W, Lappartient E, Margogne A, et al. Concordant analysis of KRAS status in primary colon carcinoma and matched metastasis. Anticancer Res. 2010;30:4229-35.

55. Hernández-Losa J, Sanz J, Landolfi S, López-Rios F, Palacios J, Bautista MD, et al. Recomendaciones para la determinación de mutaciones de K-RAS en cáncer de colon. Rev Esp Pathol. 2012;45:76-85.

56. Goldstein NS, Armin M. Epidermal growth factor receptor immunohistochemical reactivity in patients with American Joint Committee on Cancer Stage IV colon adenocarcinoma: implications for a standardized scoring system. Cancer. 2001;92:1331-46.

57. Hemmings C, Broomfield A, Bean E, Whitehead M, Yip D. (2009) Immunohistochemical expression of EGFR in colorectal carcinoma correlates with high but not low level gene amplification, as demonstrated by CISH. Pathology. 2009;41:356-60. 
58. Rego RL, Foster NR, Smyrk TC, Le M, O'Connell MJ, Sargent DJ, et al. Prognostic effect of activated EGFR expression in human colon carcinomas: comparison with EGFR status. $\mathrm{Br} \mathrm{J}$ Cancer. 2010;102:165-72.

59. de Castro-Carpeno J, Belda-Iniesta C, Casado Saenz E, Hernández Agudo E, Feliu Batlle J, González Barón M. EGFR and colon cancer: a clinical view. Clin Transl Oncol. 2008;10:6-13.

60. Frattini $M$, Saletti $P$, Romagnani $E$, Martin V, Molinari $F$ Ghisletta $M$, et al. PTEN loss of expression predicts cetuximab efficacy in metastatic colorectal cancer patients. $\mathrm{Br} \mathrm{J}$ Cancer. 2007;97:1139-45.

61. Jhawer M, Goel S, Wilson AJ, Montagna C, Ling YH, Byun DS, et al. PIK3CA mutation/PTEN expression status predicts response of colon cancer cells to the epidermal growth factor receptor inhibitor cetuximab. Cancer Res. 2008;68:1953-61.

62. Perrone F, Lampis A, Orsenigo M, Di Bartolomeo M, Gevorgyan A, Losa $M$, et al. PI3KCA/PTEN deregulation contributes to impaired responses to cetuximab in metastatic colorectal cancer patients. Ann Oncol. 2009;20:84-90.

63. Jang KS, Song YS, Jang SH, Min KW, Na W, Jang SM, et al. Clinicopathological significance of nuclear PTEN expression in colorectal adenocarcinoma. Histopathology. 2010;56:229-39.

64. Hsu CP, Kao TY, Chang WL, Nieh S, Wang HL, Chung YC. Clinical significance of tumor suppressor PTEN in colorectal carcinoma. Eur J Surg Oncol. 2011;37:140-7.
65. Sangale Z, Prass C, Carlson A, Tikishvili E, Degrado J, Lanchbury J, et al. A robust immunohistochemical assay for detecting PTEN expression in human tumors. Appl Immunohistochem Mol Morphol. 2011;19:173-83.

66. Mao C, Yang ZY, Hu XF, Chen Q, Tang JL. PIK3CA exon 20 mutations as a potential biomarker for resistance to anti-EGFR monoclonal antibodies in KRAS wild-type metastatic colorectal cancer: a systematic review and meta-analysis. Ann Oncol. 2012;23:1518-25.

67. Shtilbans V, Wu M, Burstein DE. Current overview of the role of Akt in cancer studies via applied immunohistochemistry. Ann Diagn Pathol. 2008;12:153-60.

68. Washington MK, Berlin J, Branton P, Burgart LJ, Carter DK, Fitzgibbons PL, et al. Protocol for the examination of specimens from patients with primary carcinoma of the colon and rectum. Arch Pathol Lab Med. 2009;133:1539-51.

69. Sanjuan X, Salas A, Lloreta J, Manchon Walsh P, Colorectal Cancer OncoGuia Group. Colorectal Cancer OncoGuia: surgical pathology report guidelines. Clin Transl Oncol. 2010;12:211-3.

70. Sobin LH, Gospodarowicz MK, Wittekind Ch, editores. International Union Against Cancer (UICC) TNM Classification of Malignant Tumors. 7th ed. Oxford, UK: Wiley-Blackwell; 2009.

71. Ley $14 / 2007$ de 3 de julio, de Investigación biomédica y el Real Decreto 1716/2011 de la misma. Boletín Oficial del Estado N(2090; Sec.1.1. Paj 128434. viernes 2 de diciembre de 2011. 